\title{
Un matiz nuevo en la delimitación del ámbito subjetivo de protección de las directivas antidiscriminación: diferencia de trato entre sujetos de la misma categoría protegida.
}

\author{
Pilar Rivas Vallejo \\ Catedrática de Derecho del Trabajo y de la Seguridad Social. Universidad de \\ Barcelona
}

Resumen: El ámbito subjetivo de la protección contra la discriminación por discapacidad abarca a cualquier diferencia de trato conectada con la condición protegida, aunque esta se dispense comparativamente frente a otros trabajadores que también padecen una discapacidad, sobre la base de la fecha en la que esta fue certificada y acreditada frente al empresario.

Palabras clave: Discriminación. Discapacidad. Discriminación por discapacidad. Acreditación. Salario. Discriminación directa. Discriminación indirecta

Abstract: The subjective scope of protection against disability discrimination covers any difference in treatment connected with the protected condition, even if it is dispensed comparatively compared to other workers who also suffer from a disability, based on the date on which it was certified or shown to the employer.

Keywords: Discrimination. Disability. Discrimination on grounds of disability. Certification. Salary. Direct discrimination. Indirect discrimination.

\section{Introducción}

La sentencia analizada estudia el concepto de discriminación por discapacidad y si este alcanza a las diferencias de trato no solo dispensadas a trabajadores con discapacidad frente a quienes no padecen grado alguno de discapacidad sino también a trabajadores con discapacidad frente a otros trabajadores igualmente protegidos, creándose por el empresario diferentes categorías de trabajadores sobre la base de un criterio aparentemente neutro pero realmente arbitrario como es la fecha de presentación de su certificado de discapacidad ante la empresa.

\section{Identificación de la resolución judicial comentada}

Tipo de resolución judicial: sentencia.

Órgano judicial: Tribunal de Justicia de la Unión Europea (Gran Sala)

Fecha de la sentencia: 26 de enero de 2021.

Tipo y número procedimiento: cuestión prejudicial, asunto C-16/19.

ECLI:EU:C:2021:64 
Ponente: K. Lenaerts, Presidente.

\section{Problema suscitado. Hechos y antecedentes}

\section{1. ¿Distinguir dentro de un colectivo protegido es discriminatorio?}

El problema que se suscita es el de determinar si constituye discriminación, ya sea directa ya sea indirecta, la diferencia de trato cuando esta se produce entre individuos de un mismo grupo en atención a una característica protegida por la normativa anti discriminación, en este caso la normativa de la Unión Europea y en concreto la Directiva 2000/78, y no por referencia a otros individuos no amparados por la protección específica dispensada a los individuos correspondientes a tal categoría (en este caso personas con discapacidad). En definitiva, si cabe considerar a tales efectos una comparación no entre personas con discapacidad y aquellas otras sin ella, sino entre personas con discapacidad. Esto es, si debe reputarse discriminatoria a los efectos de la Directiva 2000/78 la diferencia de trato no justificada dispensada a ciertos trabajadores con discapacidad frente a otros que también tienen una discapacidad.

En el caso analizado, tal diferencia de trato es de orden retributivo y se basa en la distinción entre dos colectivos en función de la fecha en la que acreditaron su condición de trabajadores con discapacidad, puesto que la decisión empresarial de conceder el complemento retributivo por discapacidad tiene una aplicación temporal que excluye todos los casos anteriores a la misma, proyectándose ad futurum o con efectos ex nunc. Por consiguiente, la cuestión jurídica es si el concepto y protección dispensada por la Directiva 2000/78 exige la comparación entre individuos de una característica protegida frente al resto o tiene carácter universal.

\section{Los hechos}

La trabajadora (VL), psicóloga en el hospital demandado, obtuvo un certificado de discapacidad, calificada como moderada y permanente, que compartió con la empresa el 21 de diciembre de 2011. La empresa decidió conceder un complemento salarial mensual por importe de 250 eslotis polacos (PLN) a los trabajadores que le entregasen, a partir del segundo semestre de 2013, un certificado de discapacidad, con la finalidad de reducir las cotizaciones empresariales, pero excluyó a quienes lo hubieran presentado con anterioridad a tal fecha, entre los que se encontraba la demandante (el beneficio se concedió a trece trabajadores y se denegó a dieciséis).

Por otra parte, el art. 21, de la ustawa o Rehabilitacji zawodowej i społecznej oraz zatrudnianiu osób niepełnosprawnych (Ley sobre la Readaptación Profesional y Social y el Empleo de Personas con Discapacidad), de 27 de agosto de 1997 (Dz. U. n. ${ }^{0} 123$, posición 776), establece la obligación de las empresas que empleen a veinticinco o más trabajadores a tiempo completo de abonar mensualmente al Fondo Estatal para la Readaptación de Personas con Discapacidad (PFRON) una cotización mensual de un importe calculado sobre un porcentaje dependiente del número de trabajadores que constituye la cuota de reserva de puestos de trabajo para personas con discapacidad (fijada esta en un $6 \%$ de la plantilla) cuando no alcancen dicha cuota, es decir, a modo de "penalización" económica por no cumplir con la cuota de reserva (o de obligación subsidiaria a esta, pues la legislación polaca no establece el deber de adoptar ajustes razonables en aplicación del art. 5 de la Directiva 2000/78). De suerte que resulta determinante la acreditación de la condición de persona con discapacidad a los efectos de dicha cotización, pues, de igualar o superar la cuota del $6 \%$, la empresa queda exenta del pago de tal cotización. $Y$ tal acreditación es la forma de fijar la condición de trabajador con discapacidad desde la fecha de presentación del correspondiente certificado a la empresa (art. 2a, apartado 1, de la misma ley citada), pues desde este momento el trabajador integra la plantilla de trabajadores con discapacidad.

De forma que el anuncio empresarial del complemento salarial a quienes presentaran la acreditación de la condición de persona con discapacidad en 2013 pretendía, en realidad, incentivar a su formalización a quienes no lo hubieran hecho 
con anterioridad, para poder así acogerse a la exención de la cotización específica por alcanzar la cuota del $6 \%$.

La trabajadora demandó por discriminación a la empresa ante el Tribunal de Distrito de Cracovia-Nowa Huta, Sala Cuarta de lo Laboral y de lo Social, de Polonia, que desestimó la demanda, por considerar que tal derecho no estaba previsto en norma alguna ni reconocido en el contrato de trabajo ni mediante acto concreto de la empresa, descartando asimismo la existencia de discriminación retributiva, puesto que el complemento litigioso no estaba comprendido en el ámbito de la prohibición del art. 183a del Código del Trabajo. Contra dicha decisión, la trabajadora interpuso recurso de apelación ante el Tribunal Regional de Cracovia, que plantea como cuestión prejudicial si constituye discriminación a los efectos del art. 2 de la Directiva 2000/78 la distinción entre individuos dentro de un mismo grupo de trabajadores definidos por la misma característica protegida, siendo esta la discapacidad. Podría decirse, pues, que se trata de un caso de "intradiscriminación" (término propio que no emplea el TJUE).

\section{Posición de las partes}

La recurrente sostiene que la práctica de la empresa, consistente en reconocer el beneficio salarial solo a los trabajadores que hubieran presentado el certificado acreditativo de su discapacidad con posterioridad a determinada fecha (2013) y a no quienes lo hubieron hecho con anterioridad (2011 en el caso del demandante), y que, por tanto, parece perseguir incentivar a su solicitud a los trabajadores con discapacidad (con el fin empresarial de reducir sus contribuciones al PFRON), es discriminatoria, contraria a la Directiva 2000/78. Así lo determinó la Inspección Nacional de Trabajo, que entendió discriminatorio el criterio aplicado por la empresa.

Para la trabajadora, resulta constitutivo de discriminación el uso de un criterio arbitrario e injustificado como la fecha de presentación del certificado de discapacidad, puesto que generó una diferencia injustificada entre su situación y la de otros trabajadores con discapacidad del hospital, por lo que solicita expresamente al tribunal de apelación que plantee una petición de decisión prejudicial al Tribunal de Justicia de la Unión Europea.

La empresa (Hospital Clínico Dr. Centro de Salud Pública Independiente J. Babiński en Cracovia), así como la Comisión, sostienen que no se trata de una conducta discriminatoria, puesto que el supuesto examinado no está comprendido en el ámbito de aplicación de la Directiva 2000/78, ya que el término de comparación de la misma es precisamente el de los individuos que poseen una característica protegida frente a los que no la tienen, y sobre la base exclusiva de motivos estricta y directamente relacionados con la propia discapacidad. La empresa sostuvo en el juicio que su decisión perseguía rebajar las cotizaciones al FPRON como resultado de superar la cuota de contratación de trabajadores con discapacidad, y esta no se había superado en la fecha en la que la demandante presentó su certificado, pero sí sucedió a partir del último trimestre de 2013 gracias a la medida incentivadora cuestionada. Argumenta así que, de concederse el complemento a toda la plantilla con discapacidad, no le compensaría como alternativa al pago de la cotización descrita (pues sería incluso mayor la retribución complementaria que la cotización), y esta es la causa de establecer el criterio temporal aludido y de excluir a los trabajadores que ya hubieran presentado el certificado con anterioridad.

No obstante, la Comisión Europea confluye con los recurrentes en cuando a la finalidad del principio de igualdad de trato respecto del ámbito subjetivo de la directiva, cuya amplitud cubre cualquier discriminación basada en la discapacidad, por tanto, también respecto de otros trabajadores con discapacidad.

Las recurrentes República de Polonia y República Portuguesa se alinean con la tesis de la trabajadora, considerando que la Directiva 2000/78 también puede aplicarse cuando el empresario efectúa una distinción dentro de la categoría de trabajadores con discapacidad sobre la base de un criterio de diferenciación que (aparentemente) no está directamente relacionado con la discapacidad. 
Por su parte, el abogado general Sr. Giovanni Pitruzzella, en sus conclusiones de 18 de junio de 2020, considera que el art. 2 de la Directiva 2000/78/CE debe interpretarse en el sentido de que puede constituir una violación del principio de igualdad de trato, en forma de discriminación indirecta, la diferenciación de situaciones en el seno de un grupo definido por una característica protegida (la discapacidad), bajo las condiciones clásicas de la discriminación injustificada, esto es: siempre que concurran los siguientes requisitos: a) la diferenciación establecida por el empresario se efectúa dentro de ese grupo sobre la base de un criterio aparentemente neutral; b) ese criterio, pese a ser aparentemente neutral, está indisociablemente vinculado a la característica protegida (en este caso, la discapacidad); y c) dicho criterio no puede justificarse objetivamente con una finalidad legítima y los medios empleados para la consecución de esa finalidad no son adecuados ni necesarios (Conclusión).

\section{Normativa aplicable al caso}

Directiva 2000/78/CE del Consejo, de 27 de noviembre de 2000, relativa al establecimiento de un marco general para la igualdad de trato en el empleo y la ocupación - artículo 2 , apartados 1 y 2 , letras a) y b).

Kodeks pracy (Código del Trabajo) de Polonia, arts. 11.3, 18.3a, 18.3b y Ley sobre la Readaptación profesional y social y el empleo de personas con discapacidad, de 27 de agosto de 1997 (Polonia), arts. 2a, apfo.1 y 21.

\section{Doctrina básica}

\section{Alcance erga omnes de la igualdad de trato}

La cuestión que se plantea en la resolución comentada es si cabe discriminación dentro de una misma categoría protegida por la normativa antidiscriminatoria ("intradiscriminación"), por contraposición a la discriminación de un individuo de una categoría definida por una característica protegida frente a otros individuos que no cumplan tal condición, según el concepto de discriminación directa o, en su caso, indirecta. Pues lo que se analiza es si cabe entender que concurre discriminación a los efectos de la Directiva 2000/78 cuando se establecen diferencias de trato entre trabajadores con discapacidad en atención a un criterio concreto como es la fecha de obtención del certificado que los acredita como tales.

En definitiva, se trata de determinar si el ámbito de aplicación de la Directiva 2000/78, tradicionalmente limitado a la prohibición de actos de discriminación entre personas que se definen por una determinada característica protegida y personas que no la poseen, puede ampliarse, por vía interpretativa, para cubrir situaciones de diferenciación entre personas que poseen la misma característica protegida (en este caso, una discapacidad) (cita textual de las conclusiones del abogado general).

Tratándose de una diferencia de trato salarial (en realidad una "doble escala salarial" basada en la fecha de obtención del certificado que determina el devengo del complemento), constituye presupuesto de hecho valorar como remuneración el complemento litigioso, que la sentencia objeto de análisis conceptúa como "remuneración" a los efectos del art. 3.1 c) de la Directiva 2000/78, de acuerdo con la STJUE de 2 de junio de 2016, C, C-122/15.

Por otra parte, el principio de igualdad de trato se define en el art. 2 de dicha Directiva como la ausencia de toda discriminación directa o indirecta basada en cualquiera de los motivos mencionados en su artículo 1 , entre los que se encuentra la discapacidad. Mientras que la discriminación directa, a tenor del art. 2.2 a), consiste en situación en la que una persona sea, haya sido o pudiera ser tratada de manera menos favorable que otra en situación análoga por motivo de la discapacidad, la discriminación indirecta (art. 2.2 b) se produce cuando una disposición, criterio o práctica aparentemente neutros puedan ocasionar una desventaja particular a personas, en concreto, con una determinada discapacidad, respecto de otras personas. Y exige un término de comparación que no precisa de la identidad de las situaciones, sino de su analogía, debiendo analizarse esta "de un modo específico y 
concreto" (STJUE de 22 de enero de 2019, Cresco Investigation, C-193/17). Por otra parte, la jurisprudencia del TEDH avala también como integrante del concepto de discriminación la denegación de ajustes razonables (sentencia de 10 de septiembre de 2020, asunto GL contra Italia, 59751/15).

La primera conclusión que sienta el TJUE es que este concepto no excluye la diferencia de trato entre individuos pertenecientes al mismo grupo en razón de su característica protegida, pues, "al emplear los términos "otra» persona y "otras personas», el tenor del artículo 2, apartados 1 y 2, de dicha Directiva no permite concluir que la prohibición de la discriminación prevista por dicha Directiva se limite solamente a las diferencias de trato existentes entre personas aquejadas de una discapacidad y personas que no tienen esa discapacidad". A diferencia de la expresión "basada en», que indica que solo puede constatarse una discriminación por motivos de discapacidad, cuando el trato menos favorable o la desventaja particular de que se trate se sufren en función de la discapacidad.

La sentencia precisa que la directiva no contiene ninguna precisión en cuanto a la persona o al grupo de personas que pueden servir de referencia en la comparación para apreciar la posible existencia de tal discriminación, y que su objetivo "aboga por una interpretación del artículo 2, apartados 1 y 2, de dicha Directiva en el sentido de que esta última no limita el círculo de personas con respecto a las cuales puede efectuarse una comparación para identificar una discriminación basada en la discapacidad a las que no tienen discapacidad" (párrafo 31). Por otra parte, afirma que el trato menos favorable a un trabajador, cuando este pudiera haberse dispensado sobre la base de su discapacidad, constituye discriminación contraria al art. 2.2 a) de la Directiva 2000/78, por apoyarse en un criterio indisociablemente vinculado a esa discapacidad.

En el caso litigioso, el empresario no dio opción a los trabajadores con discapacidad que ya le hubieran entregado su certificado la posibilidad de presentarlo otra vez o de presentar uno nuevo para poder percibir tal complemento salarial, mientras a los que no lo hubieran hecho sí les permitió cumplimentar este trámite para beneficiarse del complemento, aunque ambos colectivos de trabajadores se encontraban en una situación análoga, porque todos ellos contribuyeron por igual al ahorro económico perseguido por dicho empresario, con independencia de la fecha en la que hubieran presentado su certificado de discapacidad. Esta práctica empresarial impeditiva no regulada en la ley nacional (la Ley de 27 de agosto de 1997), ni tampoco definida por el propio empresario de manera transparente, provoca efectivamente la exclusión de un grupo de trabajadores compuesto por aquellos con discapacidad acreditada y previa a la decisión empresarial, además de conocida por la empresa, por tales mismas obvias razones (puesto que la presentación previa de tal certificado al empleador convierte a este en conocedor de tal condición).

En todo caso, corresponde al órgano jurisdiccional nacional determinar si el requisito temporal impuesto por la empresa para percibir el complemento salarial controvertido constituye un criterio indisociablemente vinculado a la discapacidad de los trabajadores a los que se ha denegado dicho complemento, en cuyo caso deberá declararse la existencia de una discriminación directa basada en esa discapacidad.

\section{Las conclusiones del Abogado General}

Como sostiene el Abogado General en sus conclusiones (pár. 34), si el objetivo de la Directiva 2000/78 y jurisprudencia que la interpreta es asegurar una protección eficaz a las personas que se encuentran en una determinada situación protegida, para evitar que sean tratadas de forma distinta que personas que no se encuentran en esa situación protegida, ofreciéndole una «protección eficaz contra las discriminaciones basadas en alguno de los motivos mencionados en su artículo 1 en el marco del empleo y la ocupación, aun cuando las situaciones protegidas deban interpretarse de forma estricta, la sentencia de 17 de julio de 2008, Coleman (C-303/06, EU:C:2008:415), alude a la necesidad de «combatir todas las formas de discriminación basadas en la discapacidad». Por tanto, cuando esta diferencia de trato 
se produce contra individuos que poseen la característica protegida, aun cuando no todos ellos sean tratados por igual en el mismo sentido peyorativo (en este caso la hipotética acción positiva excluye a algunos individuos con la misma característica, la discapacidad), se encuentran igualmente bajo el ámbito de aplicación de la directiva.

En su conclusión 37, el Abogado General parte de la jurisprudencia del Tribunal de Justicia de la UE, a tenor de la cual y en aplicación del art. 13 CE (actualmente artículo 19 TFUE) del que dimana la Directiva 2000/78, el ámbito de aplicación de esta última "no puede ampliarse por analogía, ni siquiera a través de una referencia al principio general de no discriminación, a otros tipos de discriminación además de las basadas en los motivos enumerados con carácter exhaustivo en su artículo 1". En cambio, argumenta, el ámbito subjetivo de aplicación debe ser objeto de una hermenéutica más flexible, "más centrada en los objetivos globales de la directiva y en el hecho de que puede surtir un efecto útil en la lucha contra las discriminaciones en el ámbito laboral". Este es el sentido del concepto de "discriminación por asociación" surgido precisamente de la tutela hacia la discapacidad, tal y como se interpreta en la ya citada sentencia Coleman.

Efectivamente, la causa amparada sigue siendo la discapacidad, aunque el criterio arbitrario al que se imputa la discriminación no sea esta en realidad, sino el establecimiento de una fecha de efectos de su decisión distinta para unos trabajadores frente a otros, aun del mismo colectivo protegido. En esta línea, manifiesta en el párrafo 41, el elemento de comparación para apreciar si un comportamiento o actuación son discriminatorios o no suelen ser las personas que carecen de la característica protegida (puesto que la función "típica» de la Directiva 2000/78 es proteger a todos los trabajadores que se encuentran en determinadas situaciones que merecen una tutela particular frente a aquellos que no se encuentran en una de esas situaciones), pero pueden darse casos en los que la diferencia de trato se produzca dentro del grupo caracterizado por la situación protegida (la discapacidad en este caso). $Y$ en este supuesto excluir la aplicación de la directiva sería "formalista y absolutamente contrario a los objetivos que persigue" esta, consistente en "evitar que algunas personas sean tratadas de forma distinta por razón de discapacidad". Pero, para valorar si en este caso existe discriminación, hay que determinar si la diferencia de trato se basa precisamente en esa discapacidad.

En suma, lo determinante es si la discapacidad (u otra característica protegida) es la causa de la diferencia de trato, pues, de ser así, estaremos ante un caso de discriminación, ya que, según reza la sentencia Coleman, «el principio de igualdad de trato que en esta materia consagra la citada Directiva no se aplica a una categoría determinada de personas, sino en función de los motivos contemplados en el artículo 1 de la misma». De ahí que el Abogado General concluya que el TJUE debe aclarar que "también puede producirse discriminación en el seno del grupo de las personas con discapacidad precisamente porque la Directiva 2000/78 protege a los trabajadores contra cualquier diferencia de trato que guarde relación con una de las características protegidas, con independencia de quién sea la persona discriminada (una persona con discapacidad o una persona que mantenga una relación directa con una persona con discapacidad) y la persona que se tome como referencia a efectos de la comparación (una persona que no padezca una discapacidad u otra persona con discapacidad)" (párrafo 51).

Analizada la conducta empresarial para determinar si resulta discriminatoria, el Abogado General la juzga "claramente ilógica y no objetiva", pues incluso actúa en contra de la finalidad perseguida por la propia empresa al privarles del complemento salarial. Si bien el motivo de la empresa obedece a la ponderación de la ventaja económica obtenida de eludir la cotización pagando a cambio (como incentivo) a los trabajadores el complemento salarial litigioso, hay que recordar que los motivos exclusivamente económicos no bastan para excluir el carácter discriminatorio del trato conferido (párrafo 62). Y, además, el criterio de diferenciación no es el declarado formalmente (la fecha de presentación del certificado de discapacidad), completamente neutro a efectos del ahorro de la cotización, sino el económico alegado 
en el juicio. En el fondo la fecha utilizada, por tanto, no es la de presentación del certificado, sino la de su obtención, lo cual priva a los que lo obtuvieron anteriormente del beneficio salarial, de suerte que el verdadero criterio es la fecha de obtención del certificado y su consiguiente presentación a partir de finales de 2013. Llegados a este punto, este criterio y trato empresarial es discriminatorio porque "únicamente los trabajadores con discapacidad pueden obtener un certificado de discapacidad, de modo que la discapacidad es el presupuesto necesario para que un trabajador (que, en principio, ya tiene una discapacidad pero que, por motivos personales, no ha solicitado o presentado aún al empresario un certificado de discapacidad) pueda obtener y presentar al empresario tal certificado".

Finalmente, este tipo de discriminación debe calificarse como indirecta, toda vez que la medida empresarial es ajena a los fines del art. 7 de la directiva, al fundarse únicamente en un interés empresarial en obtener una ventaja económica (que, bajo nuestro ordenamiento jurídico, podría incluso considerarse fraude de ley, ex art. 6.4 C.c.), pero tampoco se basa directamente en la discapacidad, sino que se establece un criterio aparentemente neutro relacionado con ella. A diferencia de la sentencia Milkova, que excluye la existencia de discriminación porque precisamente la diferencia de trato se basaba exclusivamente en la naturaleza de la relación laboral, en este caso sí tiene una estrecha conexión con esta, pues el criterio se liga a la presentación del certificado de discapacidad (párrafo 79) y provoca una desventaja, que equipara en la práctica a los efectos considerados a los trabajadores con discapacidad con los trabajadores sin discapacidad en lo que al complemento retributivo se refiere. Pero esta es una cuestión que corresponde valorar al órgano jurisdiccional nacional, pues requiere considerar la existencia de otros medios menos lesivos para alcanzar la finalidad perseguida.

\section{Parte dispositiva}

La sentencia declara que el art. 2 de la Directiva 2000/78/CE implica que constituye discriminación el trato diferenciado (en este caso el abono de un complemento salarial) a los trabajadores con discapacidad que cumplan un trámite o condición (haber presentado un certificado de discapacidad después de una fecha elegida por el empleador) en detrimento de otros que hubieran cumplido tal condición anterioridad (quienes hubieren aportado el certificado con anterioridad a tal fecha), si la práctica en cuestión se basa en un criterio indisolublemente vinculado a la discapacidad, "en la medida en que puede hacer definitivamente imposible que cumpla este requisito temporal un grupo claramente identificado de trabajadores, integrado por el conjunto de los trabajadores discapacitados cuyo empresario conocía necesariamente la situación de discapacidad en el momento en el que estableció esa práctica".

En segundo lugar, concluye que tal práctica, aunque aparentemente neutra, "puede constituir una discriminación indirecta por motivos de discapacidad cuando resulte que ocasiona una desventaja particular a trabajadores discapacitados en función de la naturaleza de su discapacidad, en particular de su carácter ostensible o de que dicha discapacidad requiera ajustes razonables de las condiciones de trabajo, sin estar objetivamente justificada por una finalidad legítima y sin que los medios para la consecución de esa finalidad sean adecuados y necesarios".

\section{Pasajes decisivos}

El quid de la cuestión sobre el que bascula la decisión final del tribunal es la diferencia de trato dispensada a personas con discapacidad ostensible o que exija ajustes razonables frente a otras menos visibles y que solo se exteriorizan por comunicación expresa de los afectados a la empresa, pues, si esta no puede justificarse objetivamente por una finalidad legítima y por medios adecuados y necesarios en su consecución, constituiría una discriminación indirecta. Esto es lo que sucede en el caso analizado, porque no reúne tales condiciones la finalidad de ahorro de costes empresariales, pero se trata de un extremo que debe valorar el órgano judicial nacional (párrafos 57,58 y 59 ). 


\section{Comentario}

\section{1. Ámbito subjetivo de la prohibición de discriminación}

La clave de la sentencia comentada reside en la delimitación del ámbito subjetivo de la prohibición de discriminación, como ya sucediera en la sentencia Coleman, que definió el concepto de discriminación por asociación que subyace en la protección dispensada por la Directiva 2000/78.

El ámbito subjetivo de la directiva no está expresamente definido por esta, pero, al señalar como núcleo de protección la causa y no la persona, por tanto, centrándose en la característica protegida (en este caso la discapacidad, pero el concepto se extiende a todas las causas protegidas en las directivas antidiscriminación), irradia sobre todas aquellas personas que, directa o indirectamente, se vean desfavorecidas en el ámbito del empleo por dicha característica personal. De ahí que se haya matizado que esta discriminación puede ser refleja al irradiarse de forma indirecta a personas que no la padecen, pero se encuentran vinculadas a alguien que sí se encuentra en tal situación y son objeto de trato peyorativo por ello (discriminación por asociación), como se interpretó en la sentencia Coleman. El grado de tal vínculo tampoco se concreta, en tanto que lo realmente relevante es que este determine una diferencia de trato injustificada.

Esta inexistente delimitación subjetiva implica que cabe igualmente la discriminación entre iguales, en tanto la directiva no restringe su ámbito de aplicación subjetivo activo en modo alguno, pudiendo actuar como sujeto discriminador cualquier persona (o institución o entidad) aun cuando su conducta se proyecte sobre un igual, v.g. persona con discapacidad que actúa con sesgo discriminatorio sobre un trabajador con discapacidad.

En efecto, la sentencia acoge el criterio del Abogado General en el sentido de admitir como situaciones comparables las que abarcan a un espectro subjetivo que va más allá de la contraposición individuos con característica protegida frente a otros individuos sin ella.

Este análisis comporta asimismo la valoración de un segundo elemento clave: la fuente última de la diferencia de trato, que debe combinarse con el elemento subjetivo, pues solo la concurrencia de ambos confluye en la determinación de una decisión como discriminatoria si, además, tal diferencia de trato no se encuentra justificada, esto es, si, basándose en la característica protegida (la discapacidad en este caso), no está amparada por un criterio objetivo y razonable que justifique su legitimación como justificación plausible exenta de sesgo discriminatorio.

Este segundo elemento, la razón de ser de la diferencia de trato confluyendo con el elemento subjetivo fue analizado precisamente en la STJUE de 9 de marzo de 2017, Milkova (C-406/15, EU:C:2017:198), para descartar la discriminación justamente por la ausencia del necesario vínculo entre la diferencia de trato y la discapacidad, puesto que, como se verificó en tal supuesto, la motivación se ligaba a la existencia de diferentes tipologías de relaciones de trabajo y no a la discapacidad en sí misma, directa o indirectamente.

Así pues, esta sentencia comporta un paso más en la delimitación del alcance subjetivo de la protección dispensada por las directivas antidiscriminación, que refuerzan el sentido que imprime la finalidad de estas para garantizar el objetivo perseguido. Se afirma, de nuevo, que la protección debe ser integral en orden a garantizar efectivamente la ausencia de discriminación por las causas protegidas, sea cual sea el modo o técnica empleado para ello y con independencia de que la acción ejecutada a tal fin tenga solo una incidencia indirecta sobre los individuos protegidos, siempre que la motivación o razón de ser de aquella sea efectivamente distinguir injustificadamente entre personas en función de su característica personal cuando esta pertenezca a una categoría protegida. 
Así, en el caso de autos, en el mismo sentido apuntado por el Abogado General, se afirma en el párrafo 44 de la sentencia que no cabe considerar que una disposición o una práctica establece una diferencia de trato directa por motivos de discapacidad cuando se basa en un criterio que no está indisociablemente ligado a la discapacidad, como afirmó en la sentencia de 9 de marzo de 2017, Milkova, C-406/15, y de 18 de enero de 2018, Ruiz Conejero, C-270/16). Ahora bien, en lo que difiere la resolución comentada respecto del planteamiento del Sr. Pitruzzella es en la conclusión abierta acerca de la calificación de la hipotética discriminación en el caso de autos, al admitir que podría calificarse tanto de discriminación directa como de discriminación indirecta por el juez nacional. En el primer caso, la justificación razonable y objetiva que podría argüir válidamente la empresa se habría de ceñir necesariamente a los motivos previstos en el art. 2.5 de la directiva. En el segundo caso, se trataría de una medida aparentemente neutra y ajena a la característica protegida "que llevaría a desfavorecer particularmente a las personas dotadas de esa característica", en el sentido de las sentencias de 16 de julio de 2015, CHEZ Razpredelenie Bulgaria, C-83/14, y de 9 de marzo de 2017, Milkova, C-406/15. En concreto, sostiene el TJUE que el juez o tribunal nacional deberá constatar si la diferencia de trato ha podido desfavorecer a las personas con determinadas discapacidades con respecto a las personas que presentan otras discapacidades (párrafo 56), pues la directiva se refiere a la discapacidad de manera general y, por tanto, sin distinción ni limitación, a todas las discapacidades. Y, en este caso concreto, el tribunal añade un argumento no expuesto por el Abogado General, al introducir un nuevo criterio, vinculado a la naturaleza especial de la discapacidad o a su notoriedad, al precisar que deberá valorarse si, al exigir que el certificado de discapacidad se presente con posterioridad a la fecha determinada por la empresa, ello provocó el perjuicio de determinados trabajadores discapacitados debido a la especial naturaleza de su discapacidad, en particular al carácter ostensible de esta o al hecho de que dicha discapacidad requería ajustes razonables como un puesto o un horario de trabajo adaptados. Por el contrario, descarta la consideración de la verdadera esencia de la fecha impuesta por la empresa, que, como aquel afirma, en realidad es la de obtención del certificado y no la de su presentación, valoración que sustituye por la equiparación entre esta hipótesis y la simple negativa empresarial a admitir la nueva presentación del certificado obtenido con posterioridad. En realidad, lo esencial es que, obtenidos o no con anterioridad, no fueron exhibidos o presentados a la empresa, pues son principalmente trabajadores que presentan tal discapacidad quienes, en la práctica, se vieron obligados, antes de la fecha elegida a oficializar su estado de salud ante este, mediante la entrega de un certificado de discapacidad, mientras que otros trabajadores que presentan discapacidades de distinta naturaleza, por ejemplo, por ser menos graves o por no necesitar de forma inmediata ajustes razonables como los mencionados en el apartado precedente, conservan la posibilidad de realizar o no tal gestión.

\section{2. ¿Por qué no se trata de una acción positiva?}

Para deslindar esta diferencia de trato de una hipotética acción positiva, válidamente admitida en el Derecho de la UE bajo las condiciones que este exige (art. 7 de la directiva), debe analizarse, como se ha realizado en el caso litigioso reseñado, cuál es el beneficio obtenido por la categoría destinataria de este y la justificación empleada para ello. Respecto del primer aspecto, lo cierto es que con esta medida la empresa solo persigue un beneficio propio, no para la categoría protegida, aun parcialmente, pues este, el complemento salarial, solo es un medio empleado por el sujeto responsable de la conducta examinada para obtener su verdadera finalidad, que es quedar exento de un coste económico en forma de cotización específica.

El beneficio otorgado a algunos individuos de la categoría protegida es un incentivo empleado para obtener una acción por parte de aquellos, por tanto, una inversión para conseguir su propio beneficio. Atendiendo a la finalidad del medio empleado, resulta obvio que no se dirige a compensar a dicho colectivo de una desventaja social padecida como consecuencia de esa característica protegida, lo que priva a la medida del presupuesto necesario para considerarla acción positiva, amén de no reunir el resto de los requisitos que precisaría su admisión, en primer lugar porque distingue 
entre individuos de la misma categoría protegida sin justificación razonable (art. 2.2. b i de la directiva), sobre la base de un criterio arbitrario solo conveniente para sus propios intereses.

\section{3. ¿Es innovadora esta sentencia para el concepto de discriminación por discapacidad?}

El Abogado General apela en sus conclusiones al carácter innovador que la (entonces futura) resolución del TJUE haya de tener, aceptando la tesis que propone, pues significaría que "el art. 2.2 b), de la Directiva 2000/78 debería interpretarse en el sentido de que se aplica a las comparaciones entre "(algunas) personas con una discapacidad [...] respecto de otras personas» (que eventualmente también tienen una discapacidad)". Y sería una interpretación innovadora porque el ámbito subjetivo de comparación se extendería o universalizaría más allá de la comparación entre dos colectivos distintos, a la manera "tradicional", en la misma línea que la sentencia Coleman supuso para la extensión subjetiva a los individuos asociados a los pertenecientes a la característica protegida (discriminación por asociación).

Lo cierto es que esta pequeña innovación contribuye a avanzar en la delimitación tanto del concepto como, sobre todo, del alcance subjetivo de la prohibición de discriminar por motivos conectados con alguna de las causas protegidas $y$, singularmente, la discapacidad. Y ello porque clarifica que los términos de comparación no se ciñen al individuo hipotéticamente discriminado frente a quienes no poseen su característica, sino de este frente a un ámbito universal porque el peso recae en que su característica sea la causante de la diferencia de trato, sin que sea necesariamente determinante que el conjunto de los individuos con la misma característica lo hayan sido también. Si el elemento estadístico es relevante en términos de valoración indiciaria de una conducta discriminatoria, no debe jugar un papel determinante en términos negativos o excluyentes, por lo que su función se acota a su efecto positivo indiciario. En el caso analizado, no existió diferencia de trato con individuos no discapacitados, pero sí se produjo respecto de trabajadores con discapacidad, es decir, pertenecientes por igual a la categoría protegida. El elemento de comparación no debió ni debe ser, en consecuencia, los trabajadores sin discapacidad, sino el de aquellos que se encuentran en su misma situación frente al universo compuesto por el resto de los trabajadores de la plantilla. En definitiva, como apuntan tanto el Abogado General como la sentencia, se trata de examinar si existe algún vínculo o relación entre su característica protegida y la decisión empresarial que no pueda justificarse por ninguna de las razones admitidas en la directiva, singularmente las previstas en los arts. 4, 5 y 7.

Si el concepto de discriminación recibe una interpretación más restrictiva, salvando el concepto de discriminación por asociación sentado en la sentencia Coleman, como ocurre con el de discriminación por percepción, que, pese a su reconocimiento en la jurisprudencia del TEDH (STEDH de 13 de diciembre de 2005, Casos 55762/00 y 55974/00, Timishev contra Rusia y STEDH de 28 de marzo de 2017 25536/14, Škorjanec contra Croacia), no ha sido admitido por el TJUE (cfr. STJUE de 18 de diciembre de 2014, asunto C-354/13, FOA contra KL), el ámbito de aplicación subjetivo sí encuentra una más beneficiosa o expansiva aplicación en la jurisprudencia del TJUE. En definitiva, y para concluir, ha de afirmarse que seguramente debiera reconsiderar su resistencia a admitir la discriminación por percepción.

\section{Categorización entre discapacidades graves y menores y discriminación}

Distinción o categorización de discapacidades que podría derivarse de actuaciones como las enjuiciadas, toda vez que en este caso las discapacidades más severas son objeto de un trato peyorativo frente a otras menos graves, como resultado indirecto de la priorización empresarial para aplicar el beneficio salarial de las de menor alcance. Y ello porque son justo estas las que no motivaron que los trabajadores que las padecían presentaran certificado alguno de discapacidad a la empresa, ya que su grado de discapacidad no les hace tributarios de medidas de ajuste razonable por parte de la empresa, en el sentido del art. 5. Ergo todas las discapacidades son objeto 
de cómputo por igual para la determinación de la cuota de contratación, y, lo que es más importante, esta regla de equiparación a tales efectos provoca un perjuicio claro para quienes sufren discapacidades mayores que sí exigen de las empresas las adaptaciones necesarias. Este riesgo es el que pone de manifiesto la sentencia y del que debe extraerse una conclusión hábil para futuros litigios sobre discriminación por discapacidad: la categorización de grados de discapacidad que opera en perjuicio de los más severos sobre los menos graves es asimismo una discriminación por discapacidad. De suerte que las decisiones empresariales basadas en este criterio deben igualmente reputarse discriminatorias si no existe una justificación objetiva y razonable que válidamente permita admitir la diferencia de trato.

Esta es precisamente la ratio decidendi de la sentencia del TEDH de 12 de enero de 2021, asunto Ryser v Switzerland (en la misma línea que la STEDH Glor v. Switzerland, no. 13444/04, $\S 80$, ECHR 2009), en tanto se produce igualmente una diferencia de trato entre categorías diferentes de personas con discapacidad, si bien en el supuesto enjuiciado por el TEDH el perjuicio sufrido por el Sr. Ryser se debió a su discapacidad de grado menor, privándole igualmente de una ventaja económica consistente en la aplicación de una exención tributaria sí prevista para los ciudadanos con discapacidad grave y para los ciudadanos sin discapacidad (como consecuencia de su declaración de ineptitud para el servicio militar, pues los ciudadanos con discapacidad mayor están exentos del pago de la tasa que compensa la no prestación del servicio militar, mientras que los no discapacitados pueden optar alternativamente por prestar un servicio alternativo de carácter civil, posibilidad vedada para los que padecen alguna discapacidad del grado que sea). En este supuesto, también el TEDH considera contrario al art. 14 del CEDH por discriminación basada en el estado de salud el trato recibido por el demandante.

\section{Apunte final}

En el momento presente la condición de persona con discapacidad habría de interpretarse a la luz de la pandemia y su efecto estigmatizador por el TJUE, en tanto el contagio o la percepción de riesgo por parte de la empresa, por una parte, y el estigma social que puede asociarse en el ámbito del empleo a sufrir la enfermedad derivada de SARS-Cov-2 permitiría adaptar la interpretación del concepto de discriminación por percepción de la jurisprudencia del TEDH a las diferencias de trato basadas en dicha condición, no asimilables a una enfermedad crónica o de larga duración que justifica la extensión del concepto de discapacidad a situaciones o limitaciones no definitivas, cuando generen un perjuicio directamente conectado a tal condición en el ámbito del empleo. 